\title{
Cross-Cultural Adjustment and Second Language Acquisition
}

\author{
Mahdi Aben Ahmed \\ Jubail English Language and Preparatory Year Institute
}

DOI: $\underline{\text { http://doi.org/ 10.36892/ijlls.v3i1.646 }}$

$\begin{array}{ll}\begin{array}{l}\text { Received: } \\ \text { 05/04/2021 }\end{array} & \begin{array}{c}\text { Abstract } \\ \text { This study aims to examine how the process of cross-cultural adjustment affects } \\ \text { Accepted: }\end{array} \\ \text { second language acquisition for Saudi students in American universities. The } \\ \text { sample consists of a group of Saudi students studying at one of the American } \\ \text { universities in the USA. Interviews were carried out to collect data about } \\ \text { subjects' daily life experiences, feelings, ways of coping in the academic and } \\ \text { Keywords: cross- } & \text { social community, what motivates them to study English, and their attitudes } \\ \text { cultural adjustment, } & \text { toward the English language, culture, and people. The findings of this study } \\ \text { second language } & \text { suggest that there are several factors for healthier adjustment and greater } \\ \text { acquisition, } & \text { successful acquisition of a second language and t. There are other factors that } \\ \text { acculturation, } & \text { keep a number of the interviewees socially and psychologically distant from the } \\ \text { language } & \text { target population and the target culture. From the current study's findings, } \\ \text { socialization } & \text { several implications and recommendations for future research have been } \\ \text { developed to help professionals involved with international students and } \\ \text { English as a Second Language field better understand Saudis and their journey } \\ \text { towards cross-cultural adjustment and acquiring a second language. }\end{array}$

\section{INTRODUCTION}

The number of Saudi students enrolled in American higher education institutions has been steadily increasing over the past years due to the government scholarship program and the desire to improve Saudi Arabia in most fields of study and work. Because Saudi students leave their homeland and go to the U.S. to continue their education, it is expected that they will encounter some difficulties in adjusting to higher education, new language, new culture, and new social environment, and they are also expected to socialize linguistically and socioculturally. Shi (2006) noted that people experience "secondary language socialization throughout their lives whenever they enter a new community and acquire a new language".(p.1). In fact, living and studying in a culturally different society produce a variety of stresses and anxieties. Adjusting to a new culture and academic environment is an inevitable task for these newcomers. In the process of adjustment, individuals face numerous demands, choices, and problems to which they must adjust and find solutions (Klingeberg, 1976).

Speaking English fluently is the main concern that most international students have about their educational experiences in the U.S. A lack of English language proficiency will affect students' ability to take notes in the class, accomplish reading and writing assignments, express ideas in the class, understand lectures, and communicate effectively with Americans. Language fluency bears a straightforward relationship to social-cultural adjustment. Nevertheless, the association between psychological adjustment and language fluency has not always been uncomplicated.

Because previous studies in second language acquisition (SLA) have rarely investigated how social-cultural and psychological factors affect Saudi ESL adult learners' process of 
acculturation and second language learning, this study will contribute to SLA by investigating the role of the effective factors in the process of acculturation and second language learning. Moreover, Saudi ESL learners will be able to use the findings of this study to make adjustments in their own individual attitudes and motivation to increase their chance of success in the second language environment and enjoy their cultural experiences.

\subsection{Research Aims}

This study aims to assess how the process of cross-cultural adjustment of Saudi students affects their second language learning and acquisition. The study also aims to explore the patterns of cross-cultural adjustment for Saudi students studying in the USA, the common problems they face and how they cope with these problems, their attitude toward the target language, culture, and environment as well as their motivation to learn English in the target language setting.

\subsection{Research Questions}

In order to find how the process of cross-cultural adjustment of Saudi students affects their second language learning and acquisition, the researcher explored their adjustment patterns and problems they face while studying in America. Also, the researcher explored how the affective factors such as attitudes and motivation affect their adjustment to American culture and thus promoting or inhibiting their language acquisition.

The study is guided by one general research question and other sub-questions:

1. What are the patterns of cross-cultural adjustment for Saudi students studying in the USA?

2. What are the common problems they face and how do they cope with these problems?

3. What are their attitude toward the target language, culture, and environment?

4. What is the Saudi students' motivation to learn English in the target language setting?

\section{LITERATURE REVIEW}

The review supporting the foundation for this study is presented in two parts. The first part focuses on theories of cross-cultural adjustment: stages of adjustment and cultural shock, social support and language socialization, and cross-cultural adaptation. The second part focuses on concepts and theories of second language acquisition: theories of second language acquisition and affective domain and personality in SLA.

\subsection{Theories of Cross-Cultural Adjustment}

\section{A. Stages of adjustment and cultural shock}

Watkins-Goffman (2001) said that the process of acculturation or adjusting one's native culture to a new culture is complicated and not linear. Individuals shift back and forth as events change in everyday cultural context, and their progress is affected by social and cultural context. Kramsch (1998) added that the psychological factors and the behaviors regarding the host society affect the process of adjusting in a new culture (pp. 70-71).

In fact, widespread literature on the different stages of cross-cultural transition referring to the adjustments of sojourners over time exists. Wintergerst, et al., (2011) clarified four phases of cultural shock:

1. Honeymoon stage: a phase portrayed by optimism, enthusiasm, and fascination which lasts from few days to six months depending on how quickly real daily communication and coping with the new culture must start.

2. Crisis: a phase typified by aggressive and hostile behaviors towards the host country and amplified involvement with co-sojourners. 


\section{Cross-Cultural Adjustment and Second Language Acquisition}

3. Recovery: a phase typified by amplified knowledge of language and capability to cope in the new culture, a better behavior regarding the host society, and a greater sense of wit.

4. Adjustment: anxiety is dissipated to a large extent, and new traditions are received and enjoyed.

Experiencing a new civilization is an unexpected and occasionally obnoxious emotion making individuals to reassess both their native and the new host culture. Before now, cultural fright was understood to be a pessimistic occurrence like an illness or disease. The anthropologist Oberg (1960) affirmed six negative features of cultural fright including (1) a feeling of deprivation or loss pointing to the elimination of the previous status, friends, possessions, or role; (2) tension due the effort of psychological adjustment; (3) confusion in self-identity, role expectation and role definition; (4) rejection of or rejection by the current culture; (5) sense of significance as a result of not being able to survive the new environment; (6) sudden indignation and anxiety after knowing cultural differences.

Other scholars have seen cultural fright from different perspectives seeing cultural shock as a normal reaction and routine process to cultural stresses. Culture shock is generally seen as "the reaction to living in a new culture, and the experience of foreignness" (Gibson, 2010, p. 15). Most of the research on cultural shock has been descriptive. It has not tried to explain who will have more or less cultural shock (e.g. males or females); and how long they remain in a period of cultural shock. Also, the literature assumes that all people will suffer a cultural shock to some extent. This assumption needs to be empirically supported because "theoretically" some people may look for experiences of cultural shock for their enjoyment or may have positive aspects of cultural shock.

\section{B. Social support, language socialization and cross-cultural adaptation}

Social support has been viewed as a major resource in the stress and coping process and as a significant mediator of psychological adjustment (Adelman, 1988). It is established that adjustment is positively correlated to contact and interaction with Americans. Adelman (1988) emphasized the source of support and suggested that the social support and help from the host national network is of greater importance to adjustment than that from a co-national network.

As far as language is concerned, Shi (2006) argued that "Language is acquired through interactive practices and socializing routines" (p. 2). Exposure, interaction, and active participation in social activities with the help from experts and corrective feedback develop language and socio-cultural competence. Shi (2006) noted that "the approach of cross-cultural adaptation is more compatible with that of language socialization" (pp. 6-7). As the individual cross the border and enter as new culture, he or she will look for opportunities to socialize and adapt to the new culture. The individual goes through the process of "enculturation, enculturation, acculturation, and assimilation" (Shi, 2006, p. 7). However, it is expected that an individual will have conflicts between acculturating and maintaining the old and familiar culture.

\subsection{Concepts and Theories of Second Language Acquisition}

\section{A. Theories of Second Language Acquisition}

Krashen's Monitor Model has been the most widely cited and most likely criticized theory of SLA. The Monitor Model theory consists of five hypotheses: the "Acquisition-Learning hypothesis", the "Monitor hypothesis", the "Natural Order hypothesis", the "Input hypothesis", and the "Affective Filter hypothesis" (Krashen, 1985; El Motabit, 2020). 
In the Acquisition-Learning hypothesis, Krashen maintained that "adult second language learners have two ways of developing competence in a second language" (Krashen, 1985). The initial way, which is a subconscious process, is to use language in a natural communication setting exactly like the way children acquire their first language. The second way which is a conscious process is "learning", and learners learn the rules in a classroom setting. The acquisition-learning distinction is similar to Chomsky's distinction between "cognize" and "know" (1985, p. 24). "Cognize" refers to tacit and subconscious knowledge and "know" refers to conscious knowledge (Chomsky, 1975, pp.164-5).

The Monitor hypothesis states that learning and acquisition are used in very specific ways in second language performance. Krashen (1982) claimed that "formal knowledge of the rules of the target language acts as the editor or monitor of the acquired system gained through the meaningful interaction in the target language. Thus, by the use of the learned system, a learner is able to correct the deviations of speech initialized by the acquisition system, either before or after the utterance has been spoken or written".

The Natural Order hypothesis states that:

We acquire the rules of language in a predictable order, some rules tending to come early and others late. The order does not appear to be determined solely by formal simplicity and there is evidence that it is independent of the order in which rules are taught in language classes (Krashen, 1982, p. 1).

The Input hypothesis claims that humans acquire language by understanding input and receiving "comprehensible input" that are a little bit beyond their current level (Krashen, 1985, p. 2). The last hypothesis is the Affective Filter hypothesis. Dulay, Burt and Krashen (1982) defined the affective filter as follows: "The filter is the part of the internal processing system that subconsciously screens incoming language based on what psychological call affect: the learner's motives, needs, attitudes, and emotional states" (p. 46). Thus, language learners do not take in everything they hear. Their motives, needs, attitudes, and emotional statues filter what they hear and affect the rate and quality of language learning. Krashen (1985) summarized the five hypotheses by saying that "people acquire the second language only if they obtain comprehensible input and if their affective filter are low enough to allow the input in" (p. 4).

\section{B. Affective domain and personality in SLA}

Research studies indicate that attitude and motivation contribute to achievement in second language learning. Rubin and Thompson (1994) stated that attitude deals with the way learners feel about the foreign culture and its people (p. 6). In fact, research has shown a definite relationship between attitudes and success when foreign language learners have an opportunity to know people who speak the language they are studying. Positive attitudes help learners maintain their interest to achieve their goals as stated by Saville-Troike (2006). Likewise, higher motivation will enhance the opportunities to learn a new language. Motivation is a very important factor in acquiring the L2, and the learners who have the tendency, desire, and ambition to communicate in the L2 are most likely to learn (Yule, 2020).

Also, there are personal factors that influence SLA. According to Rubin and Thompson (1994), a lot of students blame teachers, subjects, and teaching materials for their lack of success in learning a new language; however, the most important factor for their lack of success is themselves (p.3). Several learner traits are relevant to learning a foreign language, and they usually appear in combination. Some of the personality factors that have been widely studied include self-esteem, extroversion, anxiety, and inhibition. 


\section{Cross-Cultural Adjustment and Second Language Acquisition}

Brown (2007) said that "Self-esteem is probably the most pervasive aspect of any human behaviour. It could easily be claimed that no successful cognitive or affective activity can be carried out without some degree of self-esteem, self-confidence, knowledge of yourself, and self-efficacy" (p. 154). Thus, it is not surprising that self-esteem is very much related to SLA, and self-confident learners are most likely to acquire the language quickly and effectively. In brief, those with more self-esteem and self-confidence tend to do better in SLA (Long \& Richards, 1987, p. 39)

Moreover, extroversion and introversion have a stable and solid relation with SLA. According to Brown (2007), "Extroversion and its opposite, introversion, are also potentially important factors in the acquisition of a second language" (p.166). Extroverted learners are active, outgoing, social, confident, and talkative. Hence, extroverted learners are the most likely to learn quickly. However, the relationship between the extroversion and SLA is not always positive. For example, some people who are extroverted and outgoing can speak fluently, but they are weak in reading and writing because they focus on the oral communication.

In addition, a high level of anxiety impacts SLA because worried learners do not have the confidence in their abilities to acquire the L2. Studies said that there is a negative correlation between the anxiety and SLA. In other words, "the lower the level of anxiety, the better the language acquisition" (Long \& Richards, 1987, p. 39). Likewise, inhibition has a crucial influence. Inhibition-- the feeling of anxiety, embarrassment and shyness-- prevents the learners from participating. According to Rubin and Thompson (1994), "people who are painfully aware of their limitations and worry about their ability to use the language are usually less willing to engage in either classroom practice or in real-world communication"(pp. 67).Thus, shyness and inhibition can stand in the way of progress in speaking a foreign language. They can also prevent a person from taking risks or seizing opportunities to practice and learn. On the contrary, learners who are eager to try new experiences are likely to learn effectively, (Dulay, et al., 1982, p. 75).

\section{METHODS}

\subsection{Participants}

The participants of this study were four Saudi students enrolled as full-time students during the fall semester in 2019. This group of Saudi students included two male undergraduate students and two female undergraduate students. The subjects were invited to participate through contact by phone and informed consent form, and all of them volunteered to participate.

\subsection{Instrument}

This study used the qualitative research method. The researcher used the interviews to collect data because qualitative interviews have several advantages. deMarrais (2004) mentioned that "Qualitative interviews are used when the researchers want to gain in-depth knowledge from participants about particular phenomena, experiences, or sets of experiences" (p. 52). Thus, a well-conducted interview can produce in-depth data not possible with a questionnaire. The interview may also result in more accurate and honest responses since the researcher can explain and clarify both the purpose of the research and individual questions. deMarrais (2004) noted that the study can follow up on incomplete or unclear responses by asking additional probing questions (p. 52). By establishing rapport and a trust relationship, the researcher can often obtain data that subjects would not give on a questionnaire (Gay, Mills \& Airasian, 2009).

\subsection{Procedures for Data Collection and Data Analysis}

I explained orally to the participants the project and its purpose and gave them the informed consent form. I collected the data through the interview, and the language used in the interviews 
was Arabic. I transcribed the interviews and translated them into English. I reviewed the data collected and extracted relevant facts that can be used to draw conclusions.

\section{RESULTS AND DISCUSSION}

The subjects of this study consisted of four Saudi students enrolled as full-time students during the fall semester, 2019. They had at least six years of English education in high schools and colleges in Saudi Arabia before coming to America, and they have stayed at least three years in America. The length of the interviews varied depending on the willingness of the subjects to talk. After interviewing them, I wrote their profiles by giving them borrowed names: Ali, Mohammed, Sara, and Fatimah.

The interview questions were fourteen questions under four groups. I analyzed the answers for my questions and came up with the following results:

\section{What were the problems that concerned you most when you first entered America and an American university? How did you resolve these problems?}

Among the data collected through interviews, the subjects had a variety of experiences coping with language problems, adjusting to a new environment, and cultural shock. The language problem was the topic most frequently mentioned by the subjects when they first came to the U.S. the language problem was reflected in having difficulties understanding native speakers because of the subjects' lack of skills in listening comprehension and oral expression. There were various ways for subjects to cope with the language problem. The subjects' approaches include exposure to mass media, taking intensive English classes, seeking help from American friends, and relying upon assistance from more capable Saudi friends.

There were other problems that Saudi students faced. Ali and Mohammed were concerned about food because they could not find most of what they used to eat. Sara and Fatimah were concerned about a cultural shock because of the big difference between American and Saudi culture.

\section{Where have you acquired your knowledge about American culture?}

All four participants acquired their knowledge about American culture through mass media or asking American teachers and advisors, or their own observation.

3. If in need of information or assistance, where do you get it? For example, where do you get information on how to prepare for courses, questions about which course to take and which professors are recommended, questions about American culture, and questions about leisure time activities?

The participants relied heavily on their fellow Saudi friends for information and assistance about their daily life and academic needs. However, all of the participants consulted their advisers for academic needs.

\section{What did you feel about the idea of coming to the U.S. where the English language is the medium of instruction?}

The subjects' previous experience with the English language and their academic majors played an important role in their feeling of using English as the instructional medium. Ali, Mohammed, and Sara who had previous contact with English had less anxiety and were better adjusted within the academic community. Fatimah's feeling was also good, but she expressed her determination to spend more time to improve her English. 


\section{Under which circumstances do you use English?}

The willingness of the participants to speak English was active. They wanted to speak whenever and wherever it was possible. However, two of the participants avoided to speak English because of their fear of making mistakes and not having enough language and cultural skills.

\section{How do you like the English language? Would you like to improve your English?}

All of the participants had positive attitudes toward the English language. Also, all of them asserted their desire to learn and improve their English to succeed in the schools and communicate effectively with Americans. They wanted to improve their English because English has become the most important and popular international language in the world.

\section{In what ways do you learn and study English besides taking English classes?}

Some of the participants looked for help from different kinds of services provided by Americans or initiated conversations with Americans, and others had contact with English electronic and printed media such as watching TV or movies.

\section{How often do you watch TV or movies in English?}

The contact with mass media was a major part of the subjects' daily life. Watching TV and movies seemed to be the major entertainments for most of the subjects. Three of the subjects stated that they spent at least one hour a day watching TV or movies, and one of them watched more than three hours per day.

9. What is your impression of American society, American culture, and American people?

The subjects' positive feelings toward American were their straightforward relationships, their respect for personal privacy, their kind, warm, and polite manner, and their respect for individuals. The subjects' positive feelings toward American culture and society were that there was more freedom, a variety of ethnic groups, more caring about animals, more emphasis on consumer rights and family values. The negative feelings that some of the subjects had about American culture and society were related to social issues such as drugs, alcohol problems, the licensing of guns, obesity, and pursuit of materialism.

10. What is your impression of American faculty members? Have you received any support from them?

Most of the subjects' social interactions within the academic community were satisfactory experiences. They felt that their American professors were supportive and concerned about their academics and lives. Ali said that American instructors understood his language barriers and were willing to help in any way they could.

11. What is your impression of the local community? Have you participated in any local community activities?

From the information revealed by the subjects it was indicated that all the subjects were satisfied with their lives in the local community. They all thought that the local community was safe, quiet, and peaceful place to stay and study. However, the majority of them reported that they had never participated in any local community activities except Mohammed. Mohammed participated in some activities because he has children and wanted his children to have fun and these activities were supported by his children' school.

\section{What are your areas of frequent contact with Americans?}

All the subjects were university students and their lives were very much cantered around the academic environment. Their areas of regular contact with native speakers occurred people at the university. Generally, they interacted and communicated with professors, department secretaries, and classmates. However, the nature of these areas of contact was passive. They were restricted to simple greeting with classmates, to discussions of academic matters, and to asking professors questions in or out of the classes.

\section{Have you visited any American families in their homes?}


Sara and Fatimah said that visiting an American's home is an effective way to acquire more cultural knowledge about the target population. All of the participants visited at least one family during their lives in America. The professors' homes were the sources that provided them with cultural knowledge about American families.

14. Do you have American friends or do you want to have American friends?

Ali had some American friends, and they were his classmates. Mohammed did not have close American friends, but he expressed his interests to have American friends. Sara did not have at all, and Fatimah had American girl friends because she wanted to know about American culture and improve her English skills.

Thus, the purpose of this study has been to explore the motivation of Saudi students to learn English in the target environment, their feelings and experiences of cultural adaptation to the new second language culture, their attitudes toward the second language, culture, and its population, and their social contact with American population.

In brief, as drawn from the results of data analysis, the answers for the research questions can be as follows:

\section{What are the patterns of cross-cultural adjustment for Saudi students studying in the USA?}

Each participant maintained emphasis on academic success as his or her primary goals, and the majority of their time was directed toward the fulfilment of academic achievement. Their lives were centred around the academic community in terms of goals and social interactions. They also looked for academic and social support from their American professors and advisers, and their more capable Saudi peers.

\section{What are the common problems they face and how do they cope with these problems?}

Language problems were the common problems that participates faced. They used different approaches to cope with language problems such as watching TV and movies, taking intensive English classes, and conversation with native speakers volunteers. Cultural difference and shocks were others common problems.

\section{What are their attitude toward the target language, culture, and environment?}

The overall attitudes of Saudi students toward the target language, population and culture were positive.

\section{What is the Saudi students' motivation to learn English in the target language setting?}

All the Saudi students were motivated to learn English in America to succeed in schools and communicate effectively with American. More importantly, they understood that status of English as an important international language, which would help them further their careers in the future and get better jobs in Saudi Arabia.

To some extent, the findings depicted consistency with idea of social support, social interaction and language socialization. The results of this study indicated that Saudi students determined to gain English by means of interaction with local speakers and to maintain social contacts with Americans. Saudi students acquired many aspects of English with help from more capable Saudi peers or the instructors, and many times in a natural communication setting.

Likewise, Krashen (1985) claimed that "adult second language learners have two independent ways to develop competence in second language: acquisition and learning". The findings indicated that Saudi students had regular contacts with Americans and mass media and thus acquired English through a real and natural setting. Also, some of these Saudi students acquired 


\section{Cross-Cultural Adjustment and Second Language Acquisition}

English through the second way namely "learning", which a conscious process, by attending English classes.

\subsection{Implications for Professionals and Program Planning}

In analyzing the cross-cultural adjustment process of the Saudi students in this study, a number of implications for professionals dealing with Saudi students and other international students can be made.

1. Schools, colleges, departments should arrange social events to facilitate international students' interaction with faculty members, staff, and American students.

2. Seminars can be organized by international programs to help international students to learn about American cultural customs.

3. English conversational partners or informal conversation classes seem to be a favorable start for international students who want to improve their oral English skills.

4. Orientations should be arranged not only at the university level, but also at schools or departmental level. This special orientation will be helpful for international students to get themselves familiar with programs offered and academic expectations.

5. Departments should inform and assist faulty members by providing continuing programs for better understanding of their international students when they serve as academic advisers.

\subsection{Suggestions for Future Research}

In fact, further studies of students groups from different countries and cultures are needed to determine the effects of cross-cultural adjustment to their SLA. These studies will help the development of comprehensive understanding regarding the relationship between crosscultural adjustment and SLA for international students staying and studying in the United States. Also, I believe it would be interesting to have a similar study of Americans staying and studying in a foreign country and acquiring a second language in order to find which factors might be similar and which factors are different.

In addition, further research should be designed with the purpose of identifying the context in which cross-cultural adjustment can be better achieved. We need research that that identifies areas of conflict ad effective adjustment strategies.

\subsection{Limitations of the Study}

Most, if not all, empirical studies cannot be generalized, and my empirical study is of no exception. Another limitation of my study is the number of participants. So, I need to have more participants and thus more data to analyze. Also, most of the participants are single. Hence, married people might have different experiences and concerns. Another limitation is the short time for this study.

Moreover, this study is limited to full-time Saudi students attending a specific university. In terms of study population, these subjects represent a very small proportion in the diversity of experiences of Saudi students in the United States. Other Saudi students in other institutions may have different understandings of acculturation and SLA. Consequently, the conclusions of this study are possibly more related to Saudi students studying in small-town universities than in big cities.

In fact, the nature of the process of acculturation is in itself a very complex and wide phenomenon, which makes it difficult to study all acculturation aspects. Thus, I have only focused on affective domain of the participants, and its relationship with cross-cultural adjustment and SLA. 


\subsection{Conclusion}

The findings of this research propose and indicate that the deciding factors for healthier adjustment and greater successful acquisition of second language were the subjects' willpower to gain the English language by means of interactions with local speakers of English, their readiness to commence and continue social interactions with Americans, their recurrent use of the English language as their foremost medium of communication wherever and whenever it is possible. The factors that had kept some of the subjects socially and psychologically distant from the target culture, the target population, and American society were their perceived incapability to communicate competently with native speakers. Moreover, their perceived lack of sufficient cultural familiarity to initiate conversations with Americans, their lack of selfconfidence, and their fear of making mistakes during conversations were other factors.

\section{References}

Adelman, M. B. (1988). Cross-cultural adjustment: A theoretical perspectives on social support. International Journal of Intercultural Relations, 12, 183-205.

Brown, H. D. (2007). Principles of language learning and teaching. New York: Pearson Education.

Chomsky, N. (1975). Reflections on language. New York: Pantheon Books.

deMarrais, K. (2004). Qualitative interview studies: Learning through experience. In deMarrais, K., \& Lapan, S. (Eds.) Foundations for research: Methods of inquiry in education and the social sciences(pp. 51-68). Mahwah, NJ: Lawrence Erlbaum Associates.

Dulay, H., Burt, M., \& Krashen, S. (1982). Language two. Oxford: Oxford University Press. El Motabit, A. (2020). Evaluating the Lexical Load of the Reading Comprehension Texts in EFL Textbooks. International Journal of Linguistics and Translation Studies, 1(1), 42-53. https://doi.org/10.36892/ijlts.v1i1.15

Gay, L. R., Mills, G. E, \& Airasian, P. W. (2009). Educational research: Competencies for analysis and applications. ( $9^{\text {th }}$ ed). Upper Saddle River: Merrill/Pearson.

Gibson, R. (2010). Intercultural business communication. Oxford University Press.

Klingeberg, O. (1976). International educational exchange: An assessment of its nature and its prospects. Mouton: The Hague.

Kramsch, C. (1998). Language and culture. Oxford: Oxford University Press.

Krashen, S. (1982). Principles and practice in second language acquisition. Oxford: Pergamon Press.

Krashen, S. (1985). The input hypothesis. London: Longman.

Long, M.H., \&Richards, J. C. (1987).Methodology in TESOL. New York: Newbury House Publishers.

Oberg, K. (1960). Cultural shock: Adjustment to new cultural environment. Practical anthropology, (4), 177-182. https://doi.org/10.1177\%2F009182966000700405

Rubin, J.,\& Thompson, I. (1994). How to be a more successful language learner. Boston: Heinle and Heinle Publishers.

Saville-Troike, M. (2006). Introducing second language acquisition. Cambridge University Press.

Shi, X. (2006). Intercultural transformation and second language socialization. Journal of Intercultural Communication, 11, 1-16.

Watkins-Goffman, L. (2001). Lives in Two Languages: an Exploration of Identity and Culture.Ann Arbor: The University of Michigan Pres.

Wintergerst, A., McVeigh, J.,\& Douglas, B. (2011). Tips for teaching culture: Practical approaches to intercultural communication. Pearson. 


\section{Cross-Cultural Adjustment and Second Language Acquisition}

Yule, G. (2020).The study of language ( $7^{\text {th }}$ Ed.). Cambridge: Cambridge University Press. 